\title{
Inflammatory-Mediated Repression of the Rat lleal Sodium-Dependent Bile Acid Transporter by c-Fos Nuclear Translocation
}

\author{
FRANK CHEN, $*$ LIN MA, * R. BALFOUR SARTOR, ${ }^{\ddagger}$ FENGLING LI, ${ }^{\ddagger}$ HUABAO XIONG, $\$$ \\ AN-QIANG SUN,* and BENJAMIN SHNEIDER* \\ *Division of Pediatric Gastroenterology, Nutrition and Liver Diseases, Department of Pediatrics and the §Immunobiology Center, \\ Mount Sinai School of Medicine, New York, New York; and †ivision of Gastroenterology, Departments of Medicine, \\ Microbiology and Immunology, University of North Carolina, Chapel Hill, North Carolina
}

Background \& Aims: Ileal malabsorption of bile salts is observed in Crohn's ileitis. We define the transcriptional mechanisms involved in cytokine-mediated repression of the rat apical sodium-dependent bile acid transporter (ASBT). Methods: ASBT regulation was studied in IL-1ßtreated IEC-6 and Caco-2 cells and in indomethacintreated rats. Results: Indomethacin-induced ileitis in Lewis rats leads to specific reductions in ileal ASBT messenger RNA and protein levels, whereas c-jun and $c$-fos are induced. The proinflammatory cytokines interleukin-1 $\beta$ and tumor necrosis factor repress the activity of the ASBT promoter in Caco-2 and intestinal epithelial cell- 6 cells. This effect is blocked by the proteasome inhibitor, MG-132, or by the phosphatidyl inositol 3-kinase inhibitor, wortmannin. Indomethacin (in vivo) or proinflammatory cytokine (in vitro) treatment leads to serine phosphorylation and nuclear translocation of cfos. Mutation of a $5^{\prime}$ activated protein (AP)-1 site inactivates the ASBT promoter, whereas mutation of the $3^{\prime}$ site abrogates the proinflammatory cytokine-mediated repression. The $5^{\prime}$ site binds a c-jun homodimer, whereas the $3^{\prime}$ site binds a c-jun/c-fos heterodimer. c-Jun overexpression enhances ASBT promoter activity, whereas a dominant negative $c$-jun construct inactivates the promoter. c-Fos overexpression represses promoter activity. A 27 base pair cis-element from the $3^{\prime}$ site in the ASBT promoter imparts cytokine-mediated downregulation to a heterologous SV40 promoter construct. Conclusions: The ASBT promoter contains 2 distinct cis AP-1 elements; the 5' element binds homodimeric c-jun and mediates basal transcription. Inflammation is associated with up-regulation, phosphorylation, and nuclear translocation of c-fos, which then represses ASBT promoter activity via binding of the $3^{\prime}$ AP-1 element by a c-fos/c-jun heterodimer.

Tntestinal reclamation of bile salts is a key component 1 of the enterohepatic circulation of bile acids. ${ }^{1} \mathrm{~A}$ number of transporters are involved in this process, including the apical sodium-dependent bile acid transporter
(ASBT), which is found on the apical surface of ileal enterocytes, renal proximal convoluted tubule cells, large cholangiocytes, and gallbladder epithelial cells. ${ }^{2-7}$ Complete genetic disruption of ASBT activity leads to congenital primary bile acid malabsorption. ${ }^{8,9}$ Pathologic bile acid malabsorption occurs in the setting of ileal inflammation or resection, and exacerbates the morbidity of Crohn's disease by potentiating diarrhea, and with extensive malabsorption, leads to depletion of the bile acid pool with the subsequent development of cholesterol gallstones and steatorrhea. ${ }^{10-15}$ A rabbit model of ileitis, which was induced by enteral administration of Eimeria magna, is associated with a significant down-regulation of ASBT function, protein, and messenger RNA (mRNA). ${ }^{16}$ Similarly, expression of ASBT mRNA is repressed in a hamster 2,4,6-trinitrobenzenesulfonic acid ileitis model. ${ }^{17}$ The molecular mechanisms underlying the inflammation-mediated down-regulation of ASBT are unknown, but are presumably related to increased levels of proinflammatory cytokines such as interleukin (IL)-1, IL-6, and tumor necrosis factor (TNF). ${ }^{18}$

The transcriptional regulation of ASBT is dependent on both activated protein (AP)-1 and hepatocyte nuclear factor- $1 \alpha .{ }^{19,20}$ Site-directed mutagenesis of either AP-1 or hepatocyte nuclear factor- $1 \alpha$ sites in the proximal regions of rat and human ASBT promoters abrogates transcriptional activity in transient transfection studies. Similarly, overexpression of hepatocyte nuclear factor- $1 \alpha$ and c-jun drives ASBT promoter construct activity. A

Abbreviations used in this paper: $\mathrm{ABP}$, apical sodium-dependent bile acid transporter binding protein; AP-1, activated protein-1; ASBT, apical sodium-dependent bile acid transporter; bp, base pair; dAP-1, downstream activator protein-1; IEC-6, intestinal epithelial cell-6; IL, interleukin; pCMV, cytomegalovirus; SV40, simion virus 40; TNF, tumor necrosis factor; uAP-1, upstream activator protein-1.

(C) 2002 by the American Gastroenterological Association 0016-5085/02/\$35.00 doi:10.1053/gast.2002.37055 
hepatocyte nuclear factor- $1 \alpha$ knockout mouse is characterized by absent ileal ASBT expression and by marked fecal bile acid wasting. ${ }^{19}$ The expression of ASBT along the longitudinal axis of the rat small intestine and during normal rat ileal development correlates with the expression of c-jun. ${ }^{20}$ Activation of AP-1 is a well-known part of the standard inflammatory cascade. ${ }^{21}$ Thus, it is not immediately obvious how inflammation, which up-regulates a transcription factor implicated in stimulation of ASBT expression, might instead lead to repression of this bile acid transporter molecule.

The following studies showed 2 distinct AP-1 elements in the rat ASBT proximal promoter. One element, which is bound by a c-jun homodimer, is involved in basic promoter activity, whereas the other element binds a c-fos/c-jun heterodimer, under inflammatory conditions, and mediates ileitis-associated or IL-1 $\beta$-stimulated down-regulation of ASBT expression.

\section{Materials and Methods}

\section{Indomethacin-Induced Ileitis}

All animal studies were approved by the Animal Care and Use Committees at the Mount Sinai School of Medicine and at the University of North Carolina. Acute ileitis was induced in female Lewis rats $(180-200 \mathrm{~g})$ by subcutaneous injection of $10 \mathrm{mg} / \mathrm{kg}$ of indomethacin daily for 2 days. ${ }^{22,23}$ Control animals were injected with sodium bicarbonate/10\% ethanol vehicle only. Forty-eight hours after the first indomethacin injection, the terminal ileum was removed. The number of ulcers was quantified; ileal mucosa was removed by scraping and was immediately snap frozen in liquid nitrogen.

RNA preparation and Northern blot analysis. Total RNA was obtained from $100 \mathrm{mg}$ of ileal mucosal scrapings by using the TRIZOL extraction method (Gibco BRL, Rockville, MD). ${ }^{24}$ Ten micrograms of total RNA was subjected to $1 \%$ formaldehyde gel electrophoresis and transferred to nylon membranes (Osmonics Inc., Westborough, MA). Blots were hybridized with radiolabeled complementary DNA probes (ASBT, ${ }^{3} \mathrm{I} 100,{ }^{25} c$-jun, ${ }^{26} c$-fos ${ }^{27}$ ), and signal intensity was quantified as previously described. ${ }^{3}$ To examine RNA sample loading differences, the same blots were reprobed with a $28 \mathrm{~S}$ ribosomal RNA oligonucleotide probe. ${ }^{28}$

Protein preparation and Western blot analysis. Brush border membrane vesicles were prepared from ileal mucosal scrapings by using cation precipitation as previously described. ${ }^{29}$ Nuclear proteins were prepared as described below. For Western blot analysis, $10 \mu \mathrm{g}$ of ileal brush border membrane vesicles, $20 \mu \mathrm{g}$ of nuclear or cytoplasmic proteins, or the entire c-fos immunoprecipitate (below) was used. Samples were electrophoresed on $12 \%$ sodium dodecyl sulfatepolyacrylamide gels overlaid with $4 \%$ of acrylamide stacking gel. The proteins were transferred to Hybond-C nitrocellulose membrane (Amersham, Piscataway, NJ), followed by blocking of nitrocellulose blots overnight at $4{ }^{\circ} \mathrm{C}$ with $5 \%$ (wt/vol) nonfat dry milk in Tris-buffered saline containing $0.1 \%$ Tween 20 (Sigma, St. Louis, MO). ASBT protein was quantified with a phosphorimager by using a previously characterized rabbit polyclonal antipeptide antibody and ${ }^{125}$ I-labelled protein A. ${ }^{3,29}$ Anti-c-jun and anti-c-fos antibodies (Santa Cruz Biotechnology, Santa Cruz, CA) were added at a dilution of $1: 1000$, and blots were incubated for 1.5 hours at room temperature. Anti- $\beta$-actin (Sigma, St. Louis, MO) and antihistone H1 (Santa Cruz Biotechnology) were added to examine the loading of cytoplasmic and nuclear proteins, respectively. Antiphosphoserine antibody (CalBiochem, La Jolla, CA) was added to detect serine phosphorylation in the immunoprecipitated c-fos proteins. Immunoreactive bands were visualized by chemiluminescence, and quantification was performed by densitometry of autoradiographs in the linear range of detection.

\section{Cell Culture}

The human colon epithelial cell line Caco-2 (HTB-37; American Type Culture Collection, Rockville, MD) was selected and used in most experiments because it contains all the trans-acting factors required for ASBT expression. ${ }^{20}$ In several studies, intestinal epithelial cell (IEC)-6 cells (CRL-1592, American Type Culture Collection), a rat small intestine epithelial cell line, were used. All cells were grown in Dulbecco's modified Eagle's medium supplemented with $4 \mathrm{mmol} / \mathrm{L}$ glutamine, $1.5 \mathrm{~g} / \mathrm{L}$ sodium bicarbonate, $4.5 \mathrm{~g} / \mathrm{L}$ glucose, 1.0 $\mathrm{mmol} / \mathrm{L}$ sodium pyruvate, $0.1 \mathrm{mg} / \mathrm{mL}$ human transferrin, and $10 \%$ fetal calf serum. Cells were grown at $37^{\circ} \mathrm{C}$ and in $5 \% \mathrm{CO}_{2}$.

Cytokines and cell stimulation. All the materials were purchased from Sigma, unless otherwise indicated. Caco- 2 cells were treated for 40 hours with $20 \mathrm{pg} / \mathrm{mL}$ IL- $1 \beta$, $100 \mathrm{ng} / \mathrm{mL}$ TNF, $2 \mathrm{ng} / \mathrm{mL}$ IL-6, $20 \mu \mathrm{mol} / \mathrm{L}$ MG-132 (BIOMOL Research Laboratories, Inc., Plymouth Meeting, PA) or $25 \mathrm{nmol} / \mathrm{L}$ wortmannin. The dose dependency of the effects of IL-1 $\beta$ or TNF on ASBT promoter-directed luciferase expression was assessed in ASBT promoter transfected cells that were treated for 40 hours at various concentrations (IL- $1 \beta$ $[1,5,10,15,20 \mathrm{pg} / \mathrm{mL}]$ or TNF $[10,25,50,75,100 \mathrm{ng} / \mathrm{mL}])$ of the agents. The roles of NF- $\mathrm{KB}$ and phosphatidylinositol 3-kinase in ASBT regulation were examined in Caco-2 cells that were pretreated with $20 \mu \mathrm{mol} / \mathrm{L}$ MG-132 or $25 \mathrm{nmol} / \mathrm{L}$ wortmannin for 1 hour, followed by treatment of the cells with IL-1 $\beta$ for various times $(0,6,12,18,24$, or 36 hours).

\section{Plasmid Constructs}

A series of hybrid plasmid constructs containing different ASBT 5' sequences and a downstream firefly luciferase reporter gene were generated to localize the promoter cis elements, as described previously. ${ }^{20}$ One of the constructs, pGL3-ASBT5 $/^{\prime-208 /+118}$, which contains the shortest ASBT 5' promoter sequence, was used in the current studies. This construct contains a downstream 326-base pair (bp) ASBT 5' sequence that possesses major promoter activity. This activity is mediated by an AP-1 cis element that is located $23 \mathrm{bp}$ upstream of the transcription initiation site. 
The role of the downstream AP-1 (dAP-1) cis-trans interactions in the regulation of ASBT5' promoter activity was investigated by site-directed mutagenesis (see below) and by introducing this element in a heterologous promoter system. A 45-bp DNA fragment (ASBT sequence in capital letters, consensus sequence underlined, and restriction site linker in lowercase letters) containing a 27-bp dAP-1 sequence (5'ggcaagcttGGACTTTTTATGATTCATTATTTGTGCccatggccg- $3^{\prime}$ ) was synthesized. It was then subcloned (SV40/dAP-1) downstream of the SV40 promoter found in the luciferase reporter plasmid pGL3-Promoter (Promega, Madison, WI). A corresponding control plasmid, SV40/ZErO, was made by insertion into the same site of a nonspecific, 27-bp pZErO-1 plasmid DNA sequence (5'-ggcaagcttGGTACCGAGCTCGGATCCACTAGTAACccatggccg- $\left.3^{\prime}\right)$.

The roles of c-jun and c-fos in ASBT5' promoter-mediated gene expression were investigated by using positive and dominant-negative expression vectors. Reporter assays were performed by using cells cotransfected with pGL3-ASBT5 ${ }^{\prime}-208 /+118$ and a $c$-jun-containing (pCMV/c-Jun) or a $c$-fos-containing plasmid (pCMV/c-Fos; generous gifts from Dr. Scott Plevy, Mount Sinai School of Medicine, New York, NY). pCMV/ c-Jun and $\mathrm{pCMV} / \mathrm{c}$-Fos contain intact human $c$-jun and $c$-fos genes that encode functional c-jun and c-fos proteins, respectively. ${ }^{30}$ The c-jun-dominant negative plasmid pTAM-67 contains a c-jun sequence that has a 67-bp deletion of transacting domain and an intact DNA-binding domain. ${ }^{31}$ The c-fosdominant negative plasmid pCMV500-8584hep-fosLZ(MO) (Dr. Charles Vinson, National Cancer Institute, National Institutes of Health, Bethesda, MD) harbors a 300-bp, transacting domain-deleted $c$-fos gene sequence. ${ }^{32}$

Site-directed point mutagenesis. A QuikChange Site-directed Mutagenesis Kit (Stratagene, LaJolla, CA) was used to introduce specific mutations in pGL3-ASBT5 ${ }^{\prime}-208 /+118$, following procedures as described by the manufacturer. Two AP-1 elements were targeted, which are contained in the ASBT 5' major promoter region $\mathrm{P} 3$, ranging from -208 to +118 . The construct, pGL3-ASBT5 $/^{-208 /+118}$, which has this intact fragment inserted, was used as the template plasmid. DNA oligos were synthesized and used as primers that contain single-point mutations corresponding to 1 or 2 nucleotides of the 2 AP-1 cis elements. As a result of the technique, 3 PCR-synthesized plasmids were made, pGL3-ASBT5'/P3M1, pGL3-ASBT5'/P3M2, and pGL3-ASBT5'/P3M3, which contain point mutations in the upstream (uAP-1), downstream (dAP-1), or both AP-1 sequences, respectively. The plasmids were examined for their sizes by electrophoresis, and the point mutations were confirmed by DNA sequencing.

Reporter assays. The procedures for transient transfection and firefly luciferase analysis of cells were carried out as described previously. ${ }^{20}$ All transfections were performed in triplicate and replicated in 3 separate sets of experiments (i.e., 9 individual data points for each experimental transient transfection). Briefly, $5 \times 10^{6}$ cells per plate ( 3 plates per group) were used in each transfection executed by electroporation at $0.22 \mathrm{kV}$ and $950 \mu \mathrm{F}$ (Bio-Rad, Hercules, CA). Cells of each plate were cotransfected with $4 \mu \mathrm{g}$ of the testing plasmid constructs together with $0.1 \mu \mathrm{g}$ of a quantitative control plasmid pRL-TK (Promega, Madison, WI) containing a thymidine kinase promoter-driven Renilla luciferase gene. For cell transfections with dominant negative $c$-jun or $c$-fos, $20 \mu \mathrm{g}$ of the plasmids were used. This insured that there was full competition for the DNA-binding activities of the endogenous counterparts. After electroporation, the cells were cultured for an additional 40 hours before dual luciferase assays (Promega, Madison, WI), using the standard procedures as described by the manufacturer.

Cytoplasmic and nuclear protein extraction. Nuclear and cytoplasmic extracts were prepared from rat ileal mucosal scrapings or cultured cells by using previously described techniques. ${ }^{20}$ The procedures essentially described by Zerivitz and Akusjarvi ${ }^{33}$ were used for preparations of cytoplasmic and nuclear extracts from logarithmically growing Caco- 2 cells untreated or treated for 40 hours with IL-1 $\beta$, TNF, or IL-6. The methods were also used to prepare cytoplasmic and nuclear extracts from ileal epithelium of rat injected with indomethacin or a vehicle control. The nuclear and cellular extracts were dialyzed overnight, aliquoted into vials, quick-frozen, and stored at $-80^{\circ} \mathrm{C}$. The concentrations of nuclear and cellular proteins were determined by using a Bio-Rad protein assay kit (Bio-Rad, Hercules, CA).

Band shift assays. Band shift assays were performed with $5 \mu \mathrm{g}$ of cytoplasmic or nuclear proteins. Proteins were incubated at $37^{\circ} \mathrm{C}$ for 30 minutes with $2 \times 10^{5} \mathrm{cpm}$ of ${ }^{32} \mathrm{P}$-labelled DNA probe in $15 \mathrm{mmol} / \mathrm{L} \mathrm{KCl}, 5 \mathrm{mmol} / \mathrm{L} \mathrm{MgCl}_{2}$, $0.25 \mathrm{mmol} / \mathrm{L}$ EDTA, $0.25 \mathrm{mmol} / \mathrm{L}$ dithiothreitol, $12 \mathrm{mmol} / \mathrm{L}$ Hepes (pH 7.9), $10 \%$ glycerol, and $200 \mathrm{ng} / \mu \mathrm{L}$ Escherichia coli transfer RNA. ${ }^{34}$ Band supershift assays were performed with $0.2 \mathrm{mg} / \mathrm{mL}$ of mouse antihuman c-jun or c-fos monoclonal antibody (Santa Cruz Biotechnology). Unbound DNA sequences were digested for 30 minutes with 127 units of DNase I (Gibco/BRL). Nonspecific protein binding was reduced by adding $5 \mathrm{mg} / \mathrm{mL}$ heparin to the mixture for a 10 -minute incubation at room temperature. Samples were then subjected to electrophoresis in a $7 \%$ native polyacrylamide gel with $0.5 \mathrm{X}$ Tris-borate-EDTA running buffer. The gels were dried and exposed to Kodak BIOMAX MS films (Kodak, Rochester, NY) at $-80^{\circ} \mathrm{C}$.

\section{Immunoprecipitation}

The method described by Anderson and Blobel ${ }^{35}$ was modified and used in immunoprecipitation experiments. Cytoplasmic and nuclear extracts prepared from ileal mucosal scrapings or cultured cells were microcentrifuged for $30 \mathrm{~min}-$ utes at $10,000 g$. The supernatants were precleared with $50 \mu \mathrm{L}$ activated, quenched Sepharose by gently shaking for 1 hour at $4^{\circ} \mathrm{C}$, followed by centrifugation for 5 minutes at $200 \mathrm{~g}$. The supernatants $(1 \mathrm{~mL})$ were mixed with $25 \mu \mathrm{L}$ of a $1: 1$ slurry of $\mathrm{Ab}$ (anti-c-fos $2 \mu \mathrm{g} / \mu \mathrm{L}$ )-Sepharose/Tris saline albumin solution $(0.01 \mathrm{~mol} / \mathrm{L}$ Tris, $\mathrm{pH} 8.0,0.14 \mathrm{~mol} / \mathrm{L} \mathrm{NaCl}, 0.025 \%$ $\mathrm{NaN}_{3}$ ), and were gently shaken for 1 hour at $4^{\circ} \mathrm{C}$. The mixtures were then washed sequentially with $0.1 \%$ Triton $\mathrm{X}-100$ 
in Tris saline albumin solution, TSA solution and $0.05 \mathrm{M}$ Tris, $\mathrm{pH}$ 6.8. SDS/sample buffer $(50 \mu \mathrm{L})$ without 2 -mercaptoethanol was added to the Sepharose pellets and heated for 5 minutes at $100^{\circ} \mathrm{C}$. After microcentrifugation for 5 seconds, the supernatants were analyzed by Western blotting (see above).

Fluorescence confocal microscopy. Indirect immunofluorescence microscopy was performed on glass coverslip-grown Caco-2 cells according to previously published methods. ${ }^{36}$ The cells were fixed and permeabilized for 7 minutes in $100 \%$ methanol at $-20^{\circ} \mathrm{C}$, followed by rehydration in phosphate-buffered saline. Nonspecific sites were blocked with normal goat serum (Gibco/BRL) for 60 minutes at room temperature before incubation with the primary antibody, mouse monoclonal anti-c-fos immunoglobulin G 2a $(0.2 \mathrm{mg} /$ $\mathrm{mL}$; Santa Cruz Biotechnology) diluted 1:100 with 2\% bovine serum albumin and $10 \%$ goat serum in phosphate-buffered saline. Incubation was carried out for 60 minutes at room temperature. After 5 washes with phosphate-buffered saline, the cells were incubated with fluorescein goat antimouse immunoglobulin $\mathrm{G}(\mathrm{H}+\mathrm{L})(2 \mathrm{mg} / \mathrm{mL}$; Molecular Probes, Eugene, OR) diluted 1:1000 with $0.5 \%$ bovine serum albumin in phosphate-buffered saline for 30 minutes at room temperature in the dark. After washing with phosphate-buffered saline, cells on coverslips were inverted onto a drop of Vectashield (Vector Laboratories Inc., Burlingame, CA). Fluorescence was examined with a Leica TCS-SP (UV) 4-channel confocal laser scanning microscope in the Imaging Core Facility Microscopy Center, Mount Sinai School of Medicine. Image resolution used a Leica $63 \times$ and/or $100 \times$ Neofluor objective, and the Leica TCS-SP software was $512 \times 512$ pixels (Leica, Northvale, $\mathrm{NJ}$ ).

Statistical analysis. Analyses of data differences were carried out by Student $t$ test for analysis of 2 means and by analysis of variance followed by Fisher's PLSD post-hoc test for multiple determinations. A value of $P<.05$ was considered statistically significant.

\section{Results}

\section{Ileal Inflammation Significantly Upregulates c-fos and c-jun and Reduces Steady-State ASBT Expression}

Ileitis was induced in Lewis rats by subcutaneous injection of indomethacin. Indomethacin-injected rats $(n=6)$ had an average of 36 ulcers in the ileum (range, 19-55), whereas control injected rats $(n=6)$ had none. Phosphorimager quantification of Northern blot analysis showed a marked reduction in steady-state ASBT mRNA levels and equal RNA loading as assessed by quantification of $28 \mathrm{~S}$ ribosomal RNA (ASBT: indomethacin, $38,900 \pm 15,800$ vs. control, 97,800 \pm 40,300, $P<0.001 ; 28$ RNA: indomethacin, $9400 \pm 1300$ vs. control, $9100 \pm 1400, \mathrm{n}=6$ in each, $P>0.05$; Figure $1 A)$. Similarly, ASBT protein levels were reduced in brush border membrane vesicles prepared from indo- methacin-treated rats (indomethacin, $11,100 \pm 1800$ vs. control, 17,600 \pm 3100, $\mathrm{n}=4$ in each, $P<0.05$, Figure $1 B$ ). Steady-state mRNA levels for $c$-fos and $c$-jun were up-regulated in indomethacin-induced ileitis (c-fos: indomethacin, $422,800 \pm 282,100$ vs. control, $136,300 \pm 55,600, P<0.0001 ; c-j u n:$ indomethacin, $69,200 \pm 23,700$ vs. control, 33,800 $\pm 16,400, P<$ 0.005 ; Figure $1 A$ ). Total cellular c-fos and c-jun protein expression were each increased by 50\% (c-fos: indomethacin $137,500+15,600$ vs. control 84,700 $\pm 18,800$, $P<0.05$; c-jun: indomethacin $127,200 \pm 13,300$ vs. control 82,600 $\pm 12,000, P<0.05$; see Figure $1 B$ ). Steady-state mRNA levels for I100, an ileal brush border hydrolase, ${ }^{25}$ were unaffected in this model of ileitis (indomethacin 16,500 \pm 2000 vs. control 16,000 \pm 1800 , $P>0.05$; see Figure $1 A$ ).

IL-1 $\beta$ and TNF down-regulate ASBT gene promoter activity. Treatment of pGL3-ASBT5 $/^{-208 /+118}$ transfected Caco- 2 cells with $20 \mathrm{pg} / \mathrm{mL}$ of IL-1 $\beta$ or 100 $\mathrm{ng} / \mathrm{mL}$ of $\mathrm{TNF}$ resulted in significant reductions in ASBT promoter-directed firefly luciferase expression (Figure 2A). Cells treated with IL-6 at the concentrations of up to $2 \mathrm{ng} / \mathrm{mL}$ showed no significant reduction in ASBT promoter activity, in comparison with the untreated cells. The inhibitory effect of IL-1 $\beta$ and TNF on ASBT promoter-directed firefly luciferase expression was also observed in the rat intestinal epithelial cell line IEC-6 transfected with the plasmid construct pGL3ASBT5 $/^{-208 /+118}$. Caco-2 cells transfected with pGL3ASBT5 $/^{-208 /+118}$ were untreated or treated with various concentrations of IL-1 $\beta(1,5,10,15,20 \mathrm{pg} / \mathrm{mL})$ or TNF $(10,25,50,75,100 \mathrm{ng} / \mathrm{mL})$, respectively. Dose-dependent reductions in ASBT promoter-directed luciferase expression were observed with IL-1 $\beta$ (Figure $2 B$ ) and TNF (data not shown).

IL-1ß mediated down-regulation of ASBT is inhibited by MG-132 and wortmannin. The signal transduction pathway between IL-1 $\beta$ and ASBT promoter down-regulation was assessed by using MG-132 and wortmannin. MG-132 is a potent cell permeable selective proteasome inhibitor that disrupts activation of NF- $\kappa \mathrm{B}$ by inhibiting I $\kappa \mathrm{B}$ degradation. ${ }^{37}$ Wortmannin is a selective inhibitor of phosphatidylinositol 3-kinase. ${ }^{38}$ Both MG-132 and wortmannin almost completely abrogated the effect of IL-1 $\beta$ on the ASBT promoter (Figure $3 A$ ). The effect of MG-132 and wortmannin was observed within 6 hours of exposure (Figure 3B). MG-132 abrogated the effect of IL-1 $\beta$ on both luciferase activity and luciferase steady-state mRNA levels (Figure $3 C$ ), indicating that the effect was not simply a general effect on protein degradation. 
A

ASBT

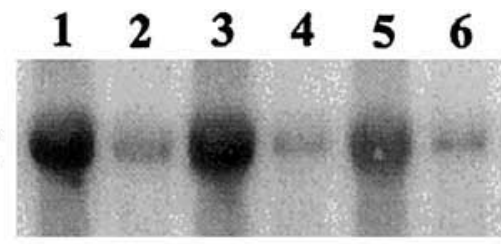

c-jun

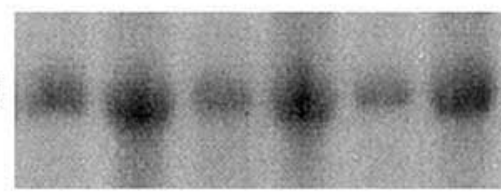

c-fos

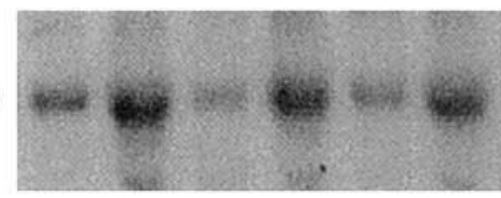

$\mathbf{I 1 0 0}$

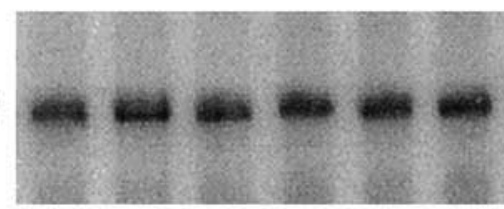

\section{S rRNA}

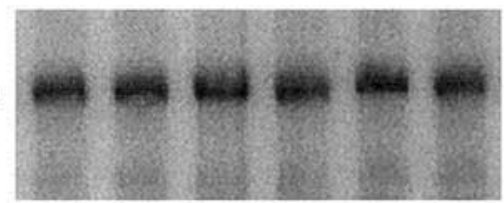

B

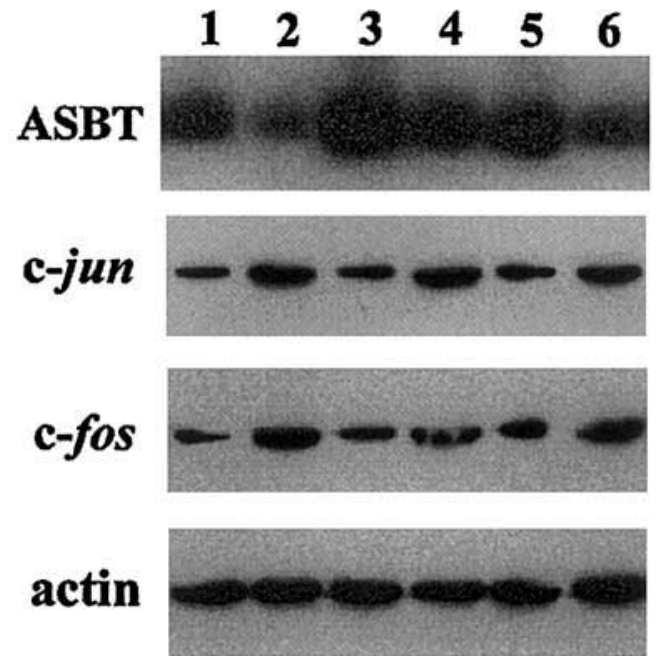

Figure 1. $(A)$ Effect of ileal inflammation on steady-state levels of ileal ASBT, c-Jun, c-Fos, and I100 mRNA levels. Ten micrograms of each total ileal RNA sample (indomethacin-induced ileitis [lanes 2, 4, and 6; each lane represents a separate animal] and control [lanes 1, 3, and 5]) was analyzed by Northern blotting. Indomethacin-induced ileitis is associated with repression of ASBT expression and enhancement of both $c$-jun and $c$-fos. Both I100 and 28S ribosomal RNA are unchanged. $(B)$ Effect of ileal inflammation on ileal ASBT, c-jun, and $c$-fos protein levels. ASBT protein in ileal brush border membrane vesicles $(10 \mu \mathrm{g})$ and $\mathrm{c}$-fos and c-jun protein in ileal cytoplasmic extracts $(5 \mu \mathrm{g})$ were measured by Western blot analysis. Expression of ASBT was repressed in the setting of indomethacin-induced ileitis (lanes 2, 4, and 6), whereas c-jun and c-fos expression was increased.
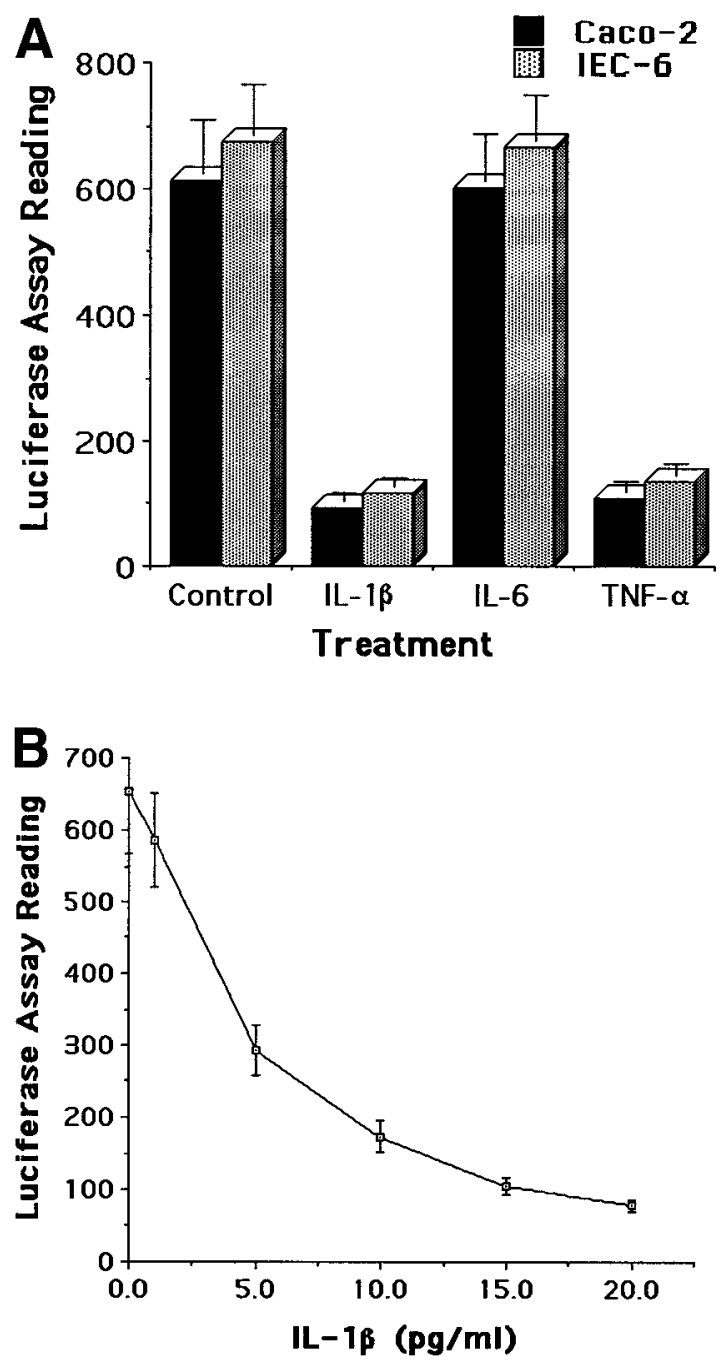

Figure 2. $(A)$ Down-regulation of ASBT promoter activity by IL-1 $\beta$ and TNF. Caco-2 and IEC-6 cells transfected with the plasmid pGL3ASBT5 $/^{-208 /+118}$ were untreated (Control) or treated for 40 hours with IL-1 $\beta$, TNF, or IL- 6 at the concentrations of $20 \mathrm{pg} / \mathrm{mL}, 100$ $\mathrm{ng} / \mathrm{mL}$, and $2 \mathrm{ng} / \mathrm{mL}$, respectively. The ASBT promoter activities represented by firefly luciferase assay readings were measured as described in Materials and Methods. In comparison with the control, both cells treated with IL-1 $\beta$ and TNF, but not IL-6, expressed significantly reduced luciferase activities $(P<0.001)$. All activities were normalized to thymidine kinase promoter-driven Renilla luciferase and each result is a mean of data obtained from at least 3 experiments (same as in other experiments as shown in Figures 3, 5, 6, and 9). (B) IL-1 $\beta$ down-regulates ASBT promoter activity in a dose-depen-

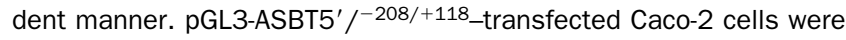
treated with IL-1 $\beta$ for 40 hours at different concentrations as shown. The results show that ASBT promoter-directed firefly luciferase expression was reduced in dose-dependent fashion.

\section{Inhibitory effects of inflammatory cytokines on} ASBT expression are mediated in part by ABP-2-DNA interactions. Previous studies have shown that at least 4 DNA-nuclear protein complexes, termed ABP-1, ABP-2, ABP-3, and ABP-4, are detected at the ASBT 5' downstream region $\mathrm{P} 3$, which is involved in the transcriptional regulation of expression of the bile acid transporter. ${ }^{20}$ One 
of these complexes, ABP-2, includes the AP-1, c-jun. Its presence correlates with developmental-stage and regionspecific expression of ASBT. In these studies, ABP-2 formation was inhibited in Caco- 2 cells treated with IL-1 $\beta$ or TNF but not with IL-6 (Figure 4). An additional previously undetected band that migrated faster than ABP-3 was also reduced after IL- $1 \beta$ and TNF treatment.

Transcriptional activation and repression of ASBT promoter activity are mediated by distinct AP-1 interactions. The proximal promoter for ASBT contains 2 distinct AP-1 binding sites. Previous reporter assays showed
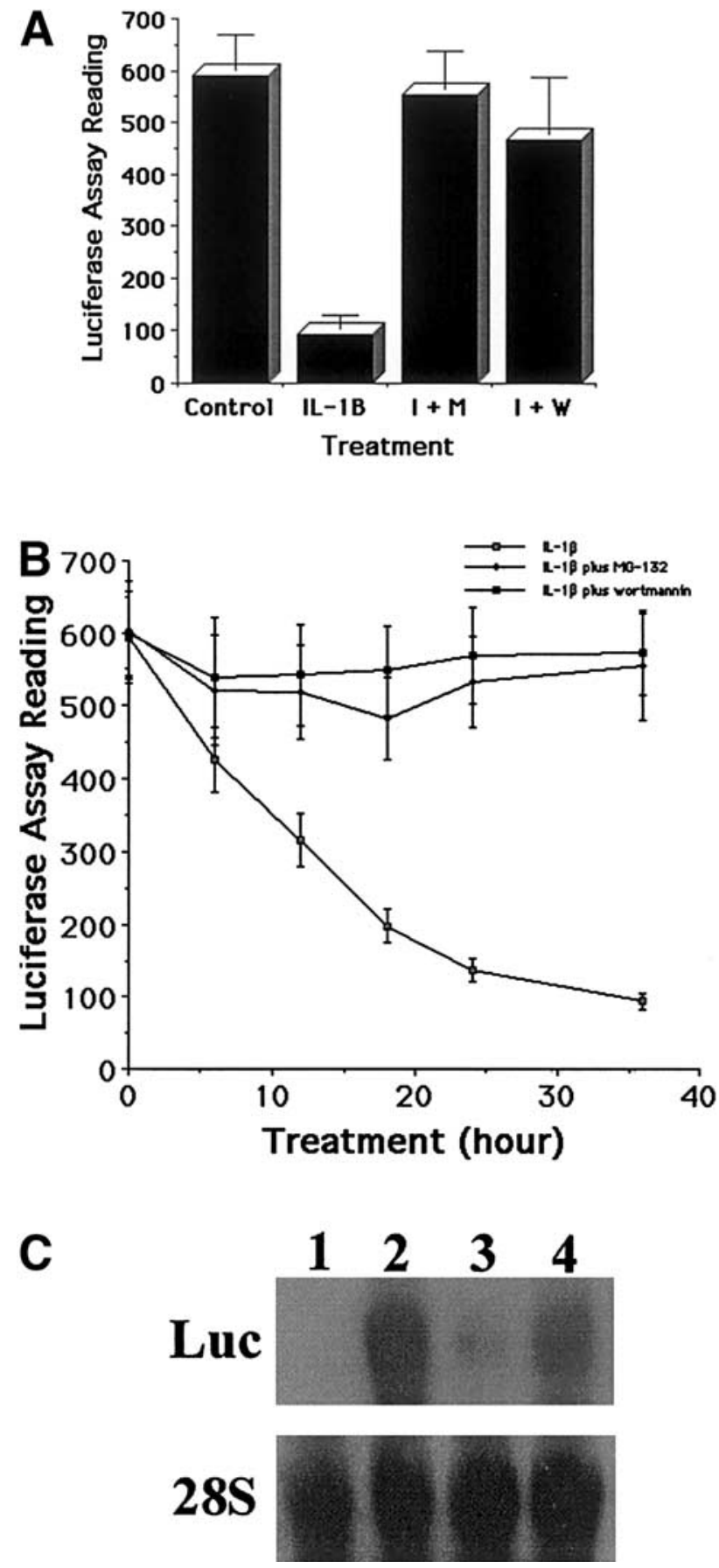

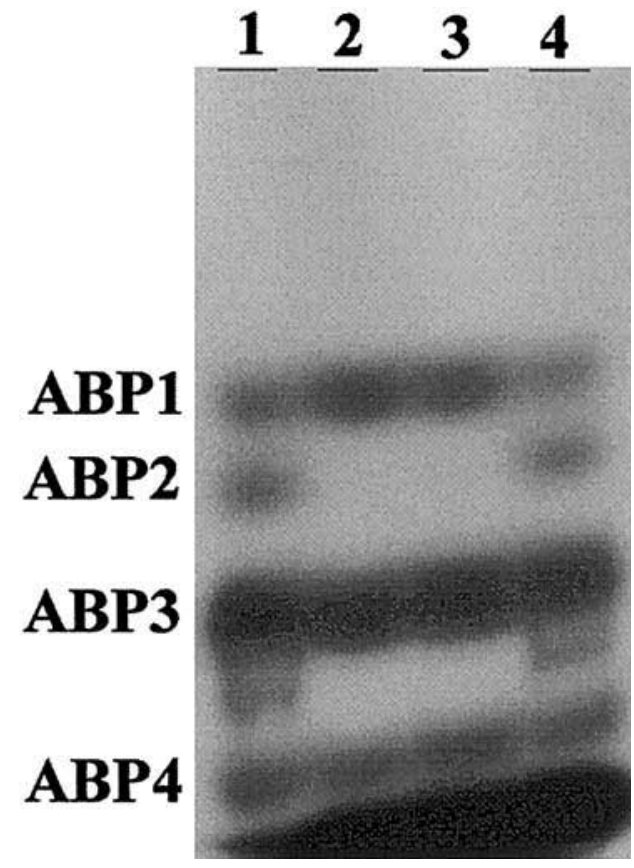

Figure 4. Effects of inflammatory cytokines on ASBT binding protein (ABP)-DNA interactions. Band-shift assay was carried out to analyze the interactions of ASBT promoter binding proteins with two AP-1 elements in ASBT promoter. The ASBT promoter fragment P3, which is contained in the hybrid plasmid construct pGL3-ASBT5 $/ /^{-208 /+118}$, was radiolabeled and incubated with the nuclear extract from (lane 1) untreated, (lane 2) TNF-, (lane 3) IL-1 $\beta$-, or (lane 4) IL-6-treated Caco- 2 cells. Four previously described ABPs are observed in the (lane 1) control cells. ABP2-DNA interaction was inhibited by treatment with (lane 1) TNF and (Iane 3) IL-1 $\beta$, but not with (lane 4) IL-6.

that site-directed point mutation of ASBT 5' uAP-1 (construct M1) or both uAP-1 and dAP-1 (construct M3) led to significant and complete inhibition of ASBT promoter activity. In light of the reduced baseline activity,

Figure 3. (A) MG-132 and wortmannin abolish IL-1 $\beta$ inhibitory effects on ASBT promoter function. pGL3-ASBT5 $/ /^{-208 /+118}$-transfected Caco-2 cells were untreated (Control) or treated for 40 hours with 20 $\mu \mathrm{mol} / \mathrm{L} \mathrm{MG}-132(\mathrm{I}+\mathrm{M})$ or $25 \mathrm{nmol} / \mathrm{L}$ wortmannin $(\mathrm{I}+\mathrm{W})$ plus 20 $\mathrm{pg} / \mathrm{mL} \mathrm{IL-1} \beta$, followed by measurement of luciferase activities. Cells treated with IL-1 $\beta$ alone (IL-1 $\beta$ ) served as a corresponding control for the groups I + W and I + M. Both MG-132 and wortmannin completely abrogate the inhibitory effect of IL-1 $\beta$ on ASBT promoter. (B) Timecourse studies of MG-132 and wortmannin inhibition of IL-1 $1 \beta$ effect. The hybrid reporter construct-transfected cells were treated with either MG-132 or wortmannin plus IL-1 $\beta$ as described previously, except the incubation times varied as shown in the Figure. IL-1 $\beta$ treatment leads to progressive reduction in ASBT promoter activity over 40 hours. The effect of IL-1 $\beta$ is immediately offset by simultaneous treatment with either MG-132 or wortmannin. $(C)$ Northern blot analysis of the effect of MG-132 on IL-1 $\beta$-mediated repression of ASBT promoter activity. No luciferase mRNA (Luc) is detected in untransfected Caco-2 cells (lane 1). Luciferase mRNA is observed in cells transfected with pGL3-ASBT5 $/^{-208 /+118}$ (lane 2) and steady-state levels are markedly reduced if cells are pretreated with $20 \mathrm{pg} / \mathrm{mL}$ of IL-1 $\beta$ (lane 3). MG-132 significantly reduces the effect of IL-1 $\beta$ on luciferase mRNA levels (lane 4). Equal loading in all lanes is shown by the signal for 28S RNA. 
no effect of IL-1 $\beta$ could be observed in M1 and M3. A point mutation in dAP-1 (construct M2) did not affect the promoter activity of $\mathrm{P} 3 .{ }^{20}$ Surprisingly, the inflammatory cytokines IL-1 $\beta$ (Figure 5) and TNF (data not shown) had no effect on M2-directed luciferase expression, in comparison with the untreated, M2-transfected cells.

Insertion of dAP-1 sequence downstream of a SV40 promoter mediates IL-1 $\beta$ down-regulation of reporter gene expression. The SV40-driven luciferase construct, the pGL3 promoter, is not responsive to IL-1 $\beta$ (Figure 6). Insertion of a 45-bp DNA fragment that contains dAP-1 downstream of this SV 40 promoter (SV40/dAP-1) modestly reduces baseline activity of the promoter and imparts responsivity to $20 \mathrm{pg} / \mathrm{mL}$ of IL$1 \beta$. IL-1 $\beta$-mediated down-regulation is inhibited by pretreatment with wortmannin. Insertion of a nonspecific 45-bp fragment (SV40/ZErO) had no effect on basal SV40 promoter activity and could not confer responsivity to IL-1 $\beta$.

UAP-1 and dAP-1 sequences within the ASBT promoter region differentially bind to the trans-acting fac-

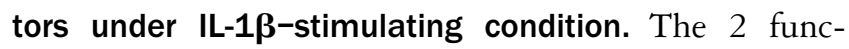
tional sequences, uAP-1 and dAP-1, are located 23-bp

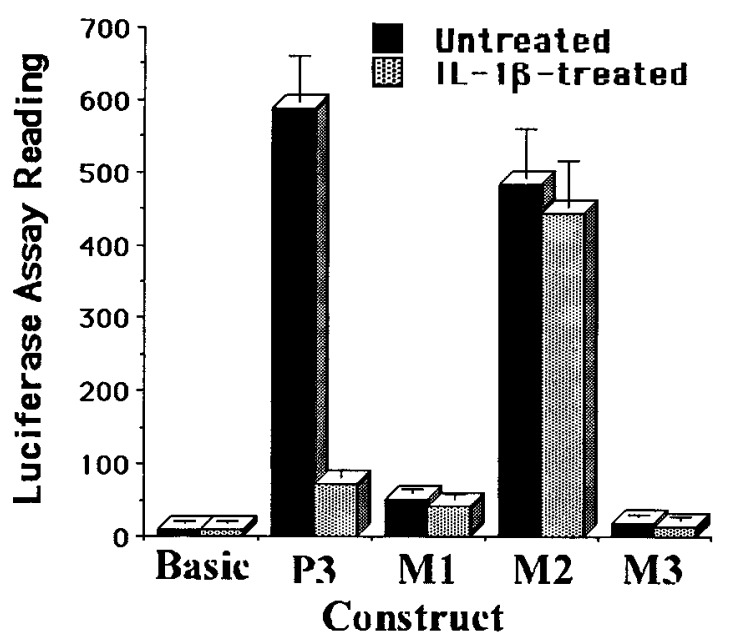

Figure 5. Site-directed mutagenesis of dAP-1 abolishes ASBT promoter response to IL-1 $\beta$ inhibitory action. Plasmid constructs containing point mutations at UAP-1 (M1), dAP-1 (M2), or both (M3) were prepared as described in Materials and Methods. Cells transfected with pGL3-Basic (Basic) or pGL3-ASBT5' / $^{-208 /+118}$ (P3), containing no promoter or ASBT P3 promoter sequence were used as negative and positive controls, respectively. Caco-2 cells transfected with these plasmid constructs were untreated or treated with IL-1 $\beta$ for 40 hours, followed by firefly luciferase assay. As shown, mutations of UAP-1 (M1) or both AP-1 sites (M3) resulted in a significant inhibition of basal ASBT promoter activity $(P<0.0001)$. The mutation of dAP-1 (M2) did not significantly affect ASBT promoter activity, compared with the positive control (P3). However, dAP-1 mutation led to failure of IL-1 $\beta$-mediated inhibition of ASBT promoter activity. Results are compiled from three separate experiments, each performed in triplicate.

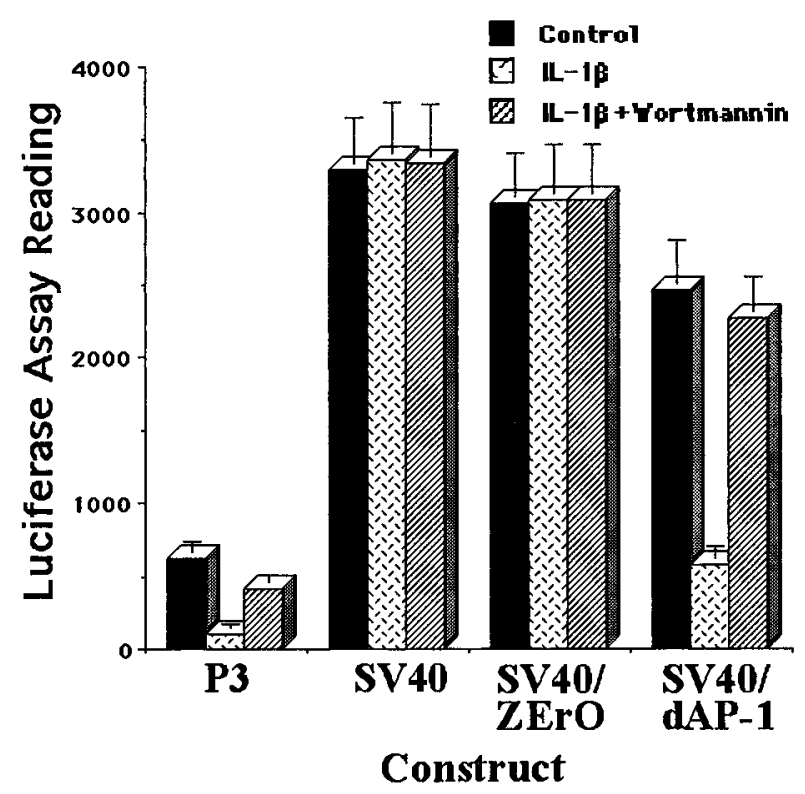

Figure 6. The dAP-1 cis element confers IL-1 $\beta$ responsivity to an SV40 promoter construct. The role of dAP-1 in ASBT promoter response to IL-1 $\beta$ was assessed by inserting dAP-1 into a heterologous promoter system. A hybrid plasmid construct SV40/dAP-1 was prepared by insertion of a $45 \mathrm{bp}$, dAP-1-containing fragment into a site, downstream of the SV40 promoter, of the plasmid pGL3-Promoter (SV40), which has no intrinsic response to IL-1ß. Caco-2 cells transfected with pGL3-ASBT5' $/^{-208 /+118}$ (P3), or SV40/dAP-1 had marked inhibitory responses to IL-1 $\beta$, which could be blocked by pretreatment with wortmannin. A control hybrid construct SV40/ZErO containing a $45 \mathrm{bp}, \mathrm{pZErO}$ plasmid sequence inserted into the same site showed no response to treatment with IL-1 $\beta$. Results are compiled from 3 separate experiments, each performed in triplicate.

upstream and 18-bp downstream, respectively, of the transcription initiation site (Figure $7 A$ ); the location of the latter for regulation of gene transcription is unusual. ${ }^{20}$ The consensus sequence for the AP-1 binding site is dependent on a terminal CA dinucleotide. The uAP-1 sequence contains a single cis element in the antisense transcriptional template strand (Figure $7 B$ ), whereas the dAP-1 sequence consists of 2 completely overlapping AP-1 cis elements, d(n)-AP1 and d(s)-AP1, which exist in the antisense and sense strands, respectively (Figure $7 C$ ). Interestingly, the uAP-1 and d(n)-AP1 cis elements in the antisense strand have the same type of sequence ( $5^{\prime}-\mathrm{TT}(\mathrm{G})$ AATCA-3'), whereas the d(s)-AP1 cis element in the sense strand is another type of AP-1 sequence $\left(5^{\prime}\right.$-TGATTCA-3'). ${ }^{39}$

Further studies were performed in Caco-2 cells to examine the trans-acting factors binding to the $2 \mathrm{AP}-1$ sequences under the IL-1 $\beta$-stimulating condition. Under native and inflammatory conditions, uAP-1 bound to nuclear (Figure $7 D$, lanes 3 and 9) and cytoplasmic (Figure $7 E$, lanes 3 and 9) c-jun only, but not to c-fos (Figure $7 D-E$, lanes 1 and 7 ). Under native conditions, 
dAP-1 was bound by c-jun alone by using nuclear extracts (Figure $7 D$, lanes 2 and 4 ) and by c-jun and c-fos by using cytoplasmic extracts (Figure $7 E$, lanes 2 and 4 ). Under inflammatory conditions, dAP-1 bound both c-

A

\section{ASBT Promoter}

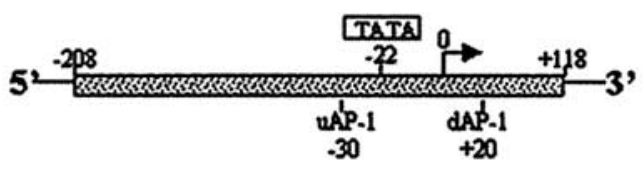

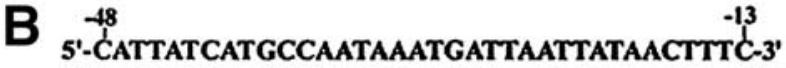 3'-GTAATAGTACGGTTATTTACTAATTAATATTGAAAG-5' uAP-1
C $+6 \quad d(8) A P-1$ 5'-TTCTGGACTTTTTATGATTCATTATTTGTGCTATGT-3' 3'-AAGACCTGAAAAATACTAAGTAATAAACACGATACA-5' d(n)AP-1

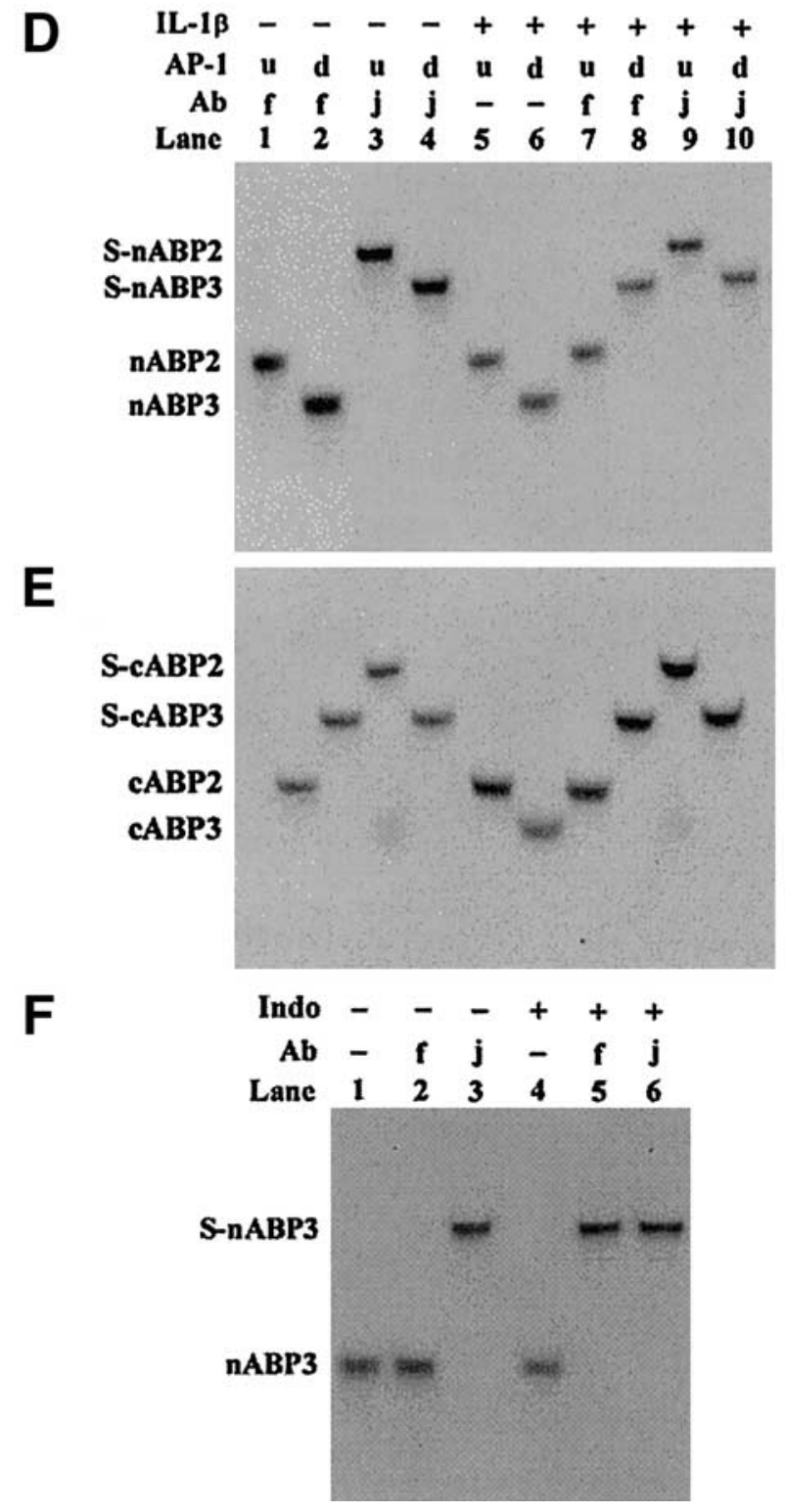

jun and c-fos by using either nuclear or cytoplasmic extracts (Figure $7 D-E$, lanes 8 and 10 ). A similar electrophoretic mobility shift assay pattern was observed by using ileal nuclear extracts from indomethacin-treated rats (Figure $7 F$ ). In vehicle-injected animals, dAP-1 bound c-jun (Figure $7 F$, lane 3) but not c-fos (Figure $7 F$, lane 2). In indomethacin-treated animals, dAP-1 bound both c-jun (Figure $7 F$, lane 6) and c-fos (Figure $7 F$, lane 5).

Western analysis of cytoplasmic and nuclear extracts of rat ileum showed that c-jun was present in both, whereas c-fos translocated from the cytoplasm to the nucleus after indomethacin treatment (Figure $8 A$ ). Indomethacin treatment was associated with serine phosphorylation of immunoprecipitated c-fos (Figure $8 B$ ). Immunofluorescence confocal microscopy was performed on Caco- 2 cells treated with IL-1 $\beta$. Under native conditions, c-fos was localized diffusely through cell in a punctate pattern, whereas IL- $1 \beta$ treatment led to nuclear translocation of c-fos (Figure 8C).

c-Jun is a transcriptional activator and c-Fos is a transcriptional repressor of the ASBT promoter. To further study the roles of c-jun and c-fos in ASBT expres-

Figure 7. IL-1 $\beta$ treatment of Caco- 2 cells and indomethacin treatment of rats leads to formation of fos/jun heterodimer and subsequent binding to dAP-1. $(A)$ Shows the schematic diagram of ASBT 5' major promoter region $\mathrm{P} 3$, which was contained in the hybrid reporter construct pGL3-ASBT5 $/^{-208 /+118}$, upstream of the firefly luciferase reporter gene. Numbers in the diagram represent the sequence positions. The transcription initiation site is numbered by 0 and indicated by arrow. The sequences of $(B)$ uAP-1 and $(C)$ dAP-1 oligo probes used in the supershift assays ( $D$ and $E$ ) are shown. The AP-1 consensus sequences are indicated by underlined [UAP-1 and $d(n) A P-1]$ and above-lined (d(s)AP-1) nucleotides. The critical CA terminal dinucleotide of the AP-1 binding site is italicized. The results obtained from the electrophoretic mobility supershift assays with the $(D)$ Caco-2 nuclear extract and $(E)$ cytoplasmic extract are shown. Under both native ( $D$ and $E, I L-1 \beta-$ ) and inflammatory $(D-E, I L-1 \beta+$ ) conditions, uAP-1 element (u) binds to only c-jun (j) ( $D-E$, lanes 3 and 9 ), but not c-fos (f) ( $D-E$, lanes 1 and 7$)$, as shown by the supershifted ABP-2 (S-nABP-2 and S-cABP-2) and the nonsupershifted ABP-2 (nABP2 and CABP2), respectively. Conversely, under the native condition, dAP-1 sequence (d) binds to only c-jun in nucleus $(D$, lanes 2 and 4), whereas the sequence binds both c-jun and c-fos from cytoplasm ( $E$, lanes 2 and 4$)$. Under the inflammatory condition, dAP-1 sequence binds c-jun and c-fos from nucleus ( $D$, lanes 8 and 10) and cytoplasm ( $E$, lanes 8 and 10$)$. The presence and absence of c-fos in nuclear and cytoplasmic protein/dAP-1 complexes are represented by the supershifted (S-nABP3 and S-CABP3) and nonsupershifted (nABP3 and $\mathrm{CABP} 3$ ) bands, respectively. $D$ and $E$, lanes 5 and 6 represent no antibody controls for the supershift analysis of UAP-1 and dAP-1 sequences, respectively. Indomethacin treatment of rats leads to an $(F)$ electrophoretic mobility shift assay pattern similar to that observed in IL-1 $\beta$-treated Caco-2 cells $(D-E)$. The dAP-1 sequence binds c-jun but not c-fos from ileal nuclear extracts of vehicle- (Indo-) treated rats $(F$, lanes 2 and 3), whereas after indomethacin treatment (Indo + ), dAP-1 sequence binds c-jun and c-fos from ileal nuclear extracts ( $F$, lanes 5 and 6$)$. u, upstream; d, downstream; s, sense strand; n, antisense strand. 
A

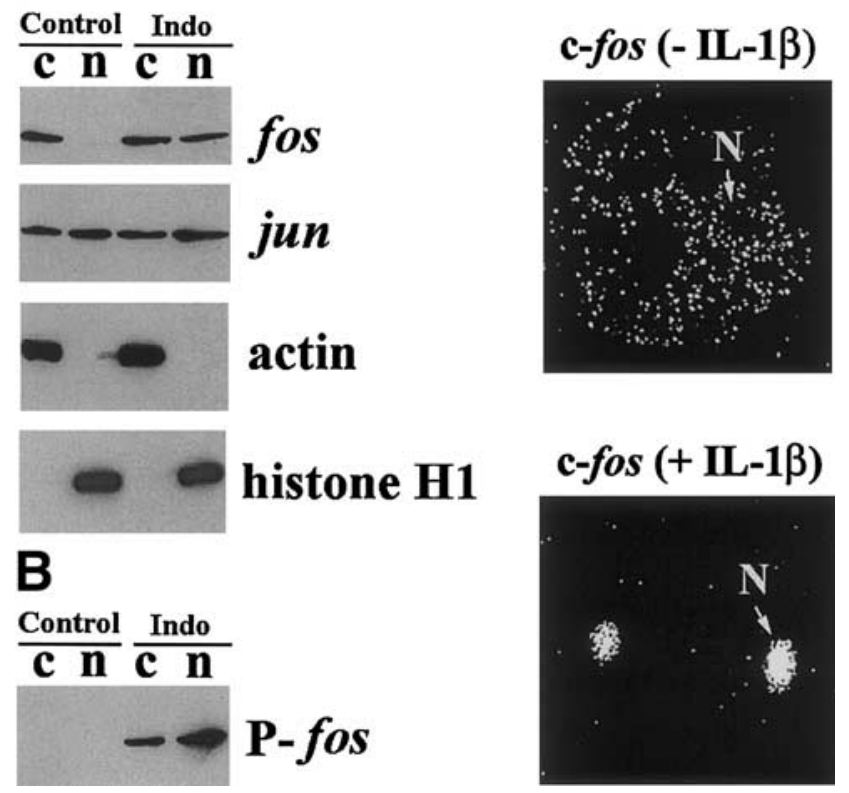

Figure 8. Inflammation is associated with phosphorylation and nuclear translocation of $\mathrm{c}$-fos. $(A)$ Indomethacin treatment induces translocation of c-fos from cytoplasm to nucleus. The induction of rat ileitis and preparation of cytoplasmic (c) and nuclear (n) extracts from rat ileal mucosal scrapings are described in Materials and Methods. Western blot analyses with $10 \mu \mathrm{g}$ of each sample were performed to examine the localization of c-jun and c-fos under inflammatory condition. c-jun is present in both cytoplasm and nucleus under control (saline) and ileitis (Indo) conditions, whereas c-fos exists in cytoplasm under native condition and translocates to nucleus after ileitis was induced. The same membrane was probed with actin and histone antibodies for examination of the cytoplasmic and nuclear protein loading, respectively. $(B) \mathrm{c}$-fos protein is phosphorylated after ileitis is induced. c-fos protein was precipitated from the nuclear and cytoplasmic extracts used in the above experiment and analyzed by Western blot analysis using a specific phosphoserine antibody as described in Materials and Methods. Phosphorylated c-fos (P-fos) is observed in both the cytoplasm and nucleus after indomethacin treatment, but not in the control condition. $(C)$ c-Fos translocates to the nucleus in Caco- 2 cells treated with IL-1 $\beta$. The top panel shows immunofluorescent localization of c-fos in native Caco-2 cells. Immunofluorescence is distributed throughout the cell in a punctate pattern. After IL-1 $\beta$ treatment, c-fos is found primarily within the nucleus ( $C$ bottom panel, 2 nuclei in field with the right one labeled with white arrow and $N$ ).

sion, positive and dominant negative expression constructs were cotransfected in Caco-2 cells with the reporter construct pGL3-ASBT5 $/^{-208 /+118}$. As previously shown, c-jun trans-activates the ASBT promoter (Figure 9A). Interestingly, c-jun inhibits the activity of pGL3-SV40/dAP-1 (Figure 9B). A dominant negative c-jun construct abrogates ASBT promoter activity in both Caco-2 (Figure 9A) and IEC-6 cells (data not shown). In contrast, overexpression of c-fos represses ASBT promoter activity in Caco-2 cells (Figure 9A). The dominant-negative $c$-fos construct also represses ASBT promoter activity (Figure 9A). This c-fos mediated repression of activity is also observed in the SV40-promoter construct that harbors the dAP-1 element, but not in SV40/Zero and SV40 promoter alone (Figure 9B).

\section{Discussion}

Intestinal inflammation is associated with a variety of abnormalities in solute transport. ${ }^{16,40-42}$ Clinical
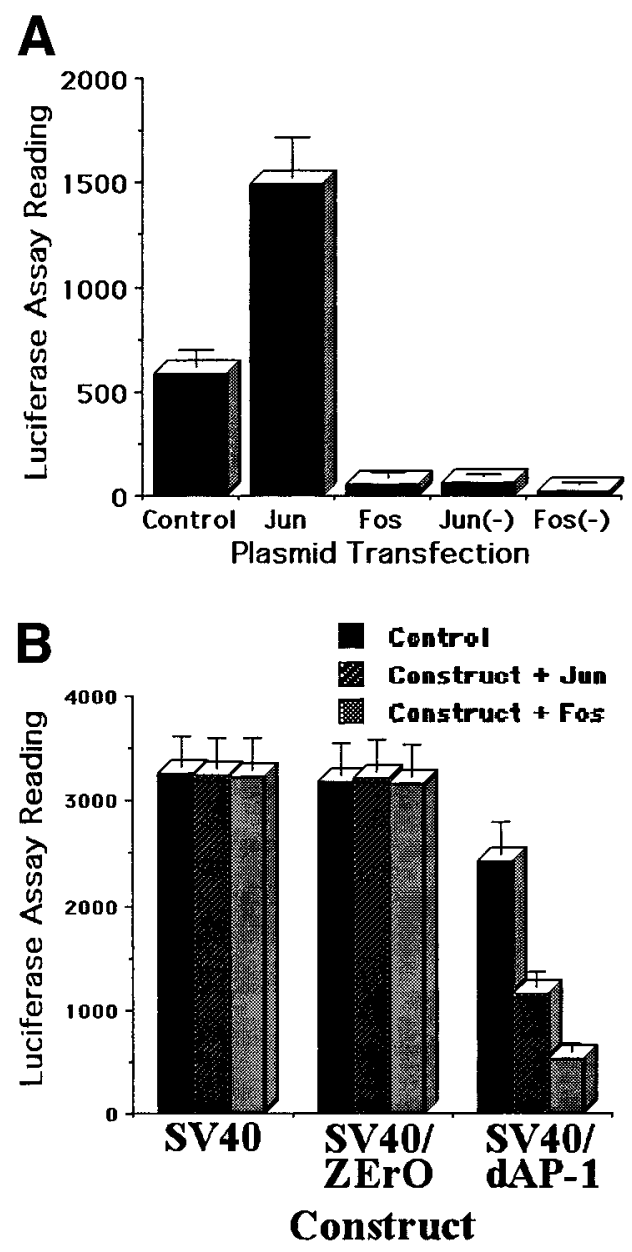

Figure 9. c-Jun transactivates and c-fos represses ASBT promoter activity via 2 distinct AP-1 binding sites. $(A)$ Effects of overexpression of wild-type and dominant negative jun and fos on ASBT promoter activity. Caco- 2 cells were transfected with pGL3-ASBT5 $^{\prime} /^{-208 /+118}$ alone (Control) or cotransfected with plasmids containing wild-type (jun, fos) or dominant negative [jun(-), fos(-)] c-jun or c-fos, respectively, as described in Materials and Methods. Wild-type jun greatly enhances ASBT promoter activity $(P<0.01)$, whereas wild-type fos and dominant negative jun and fos significantly suppress the promoter function in comparison with the control $(P<0.001)$. (B) dAP-1 from the ASBT $5^{\prime}$ region mediates jun and fos inhibitory effect on SV40 promoter activity. Luciferase assays with cells cotransfected with the hybrid construct SV40/dAP-1 and the plasmids containing wild-type c-jun or c-fos show that both the exogenous factors can significantly inhibit SV40 promoter activity, which is not affected by the 2 exogenous proteins in the presence of the promoter alone (SV40) or a 27-bp pZErO-1 plasmid sequence downstream of SV40 (SV40/ZErO). Results are compiled from 3 separate experiments, each performed in triplicate. 
studies in humans indicate that bile acid malabsorption is observed in various forms of ileitis. ${ }^{1-15}$ Molecular investigations have not yet been performed in humans to determine if this is mediated by alterations in the expression or function of ASBT. Previously, 2 distinct animal models had shown that ileitis induces marked reductions in the expression of ASBT. ${ }^{16,17}$ The current studies have shown that indomethacin-induced acute ileitis in rats is also associated with a significant downregulation of steady-state ASBT mRNA and protein levels. This finding does not appear to be a generalized phenomenon that results from mucosal injury because the expression of another brush border protein, I100, is unaffected. As expected, the AP-1 transcripts, $c-j u n$ and $c$-fos, were up-regulated in this model of ileitis. Indomethacin-induced ileitis has been previously shown in our laboratories to be associated with increased expression of inflammatory cytokines, such as IL-1 $\beta .{ }^{23}$ Therefore, further mechanistic investigations were performed in Caco-2 and IEC-6 cells treated with inflammatory cytokines.

Proinflammatory cytokines reduced the activity of the rat ASBT promoter in both Caco-2 and IEC-6 cells. Dose-dependent reductions in promoter activity were observed using either IL- $1 \beta$ or TNF. The signal transduction pathways involved in mediating the effects of proinflammatory cytokines are quite complex. ${ }^{43}$ In this in vitro system, transcriptional repression could be inhibited by pretreatment with either wortmannin or MG132, which block phosphatidylinositol 3-kinase and proteasome activity, respectively. Phosphatidylinositol 3-kinase activity may be involved in the activation of both AP-1 and NF- $\mathrm{kB} .{ }^{38,44}$ Proteasome function is important in mediating degradation of $\mathrm{I}-\kappa \mathrm{B}$ and subsequent activation of NF- $\kappa$ B. Therefore, IL- $1 \beta$ repression of ASBT is mediated through both AP-1 and NF- $\mathrm{KB}$. Activation of NF- $\kappa B$ in this system may be via more than 1 mechanism, including an I- $\mathrm{KB}$-independent system. Northern and Western blot analysis indicated that both $c$-jun and $c$-fos were up-regulated in response to ileal inflammation. Previous investigations had indicated that AP-1 played a key role in the transcriptional activation of the rat ASBT promoter, ${ }^{20}$ thus the mechanism by which activation of AP-1 might repress ASBT expression was perplexing.

The ASBT promoter contains 2 distinct AP-1 ciselements, which permit the differential effects of AP-1 trans-acting factors (Figure 10). The uAP-1 site is a positive-acting element, whereas the downstream site is involved in transcriptional repression. The upstream element binds a c-jun homodimer. Our previous report, in

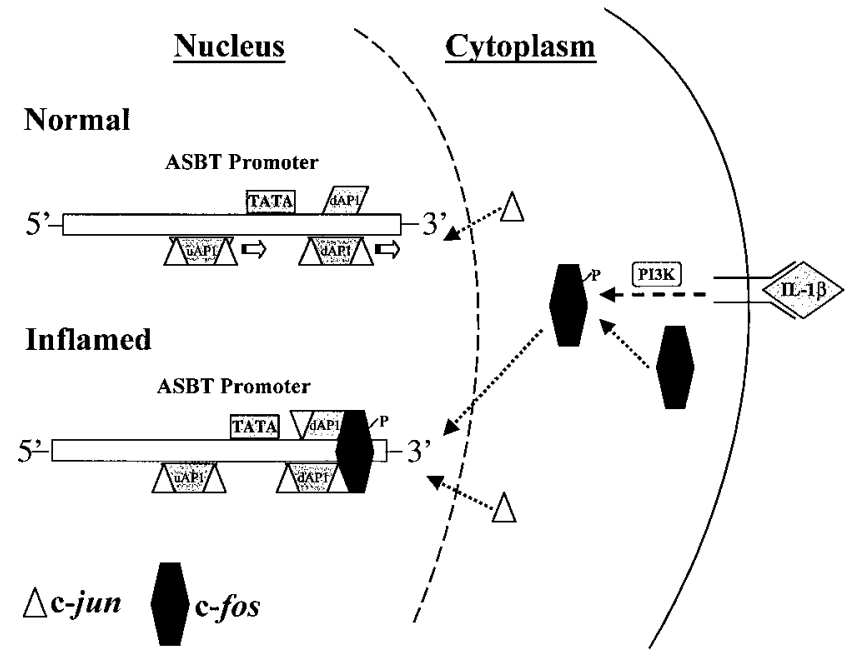

Figure 10. A novel model for ASBT regulation. Under normal conditions, c-jun binds to both UAP-1 and dAP-1 in the form of homodimer, directing ASBT expression. As ileal inflammation occurs, such as in Crohn's disease, there is increased expression of the inflammatory cytokine IL-1 $\beta$. It binds to the membrane surface receptor, initiating a cascade of signal transduction involving phosphatidyl inositol $3 \mathrm{ki}-$ nase and, potentially, NF-кB. Serine-phosphorylation of the target protein c-fos facilitates its translocation from cytoplasm to nucleus where it forms with c-jun a heterodimer, which subsequently binds to dAP-1. This dAP-1/protein complex prevents the upstream c-jun dimer from directing ASBT transcription.

retrospect, incorrectly indicated that c-fos bound to uAP-1. ${ }^{20}$ Those studies were performed with a large fragment of ASBT 5 ' flanking DNA that included both uAP-1 and dAP-1. The current investigations more thoroughly and specifically investigated the trans-acting factors that bind to the $2 \mathrm{AP}-1$ cis-acting elements found in the ASBT promoter. Overexpression of c-jun transactivates the system, whereas the system is quenched with a dominant-negative c-jun. The dAP-1 element binds a $\mathrm{c}$-jun/c-fos heterodimer. Overexpression of c-fos represses the activity of the ASBT promoter. The dAP-1 element appears to be both necessary and sufficient to mediate IL-1 $\beta$-mediated repression. Mutation of this element abrogates its effect, whereas its incorporation into a heterologous system imparts novel IL- $1 \beta$ responsivity. The repressive effect of c-jun in this heterologous system is presumed to be mediated after c-jun complexes with preexisting c-fos that is endogenously expressed in the cell lines. Alternatively, c-jun binding to the distal AP-1 element, in the absence of the positive-acting uAP-1 element may be sufficient to mediate transcriptional repression.

The exact mechanism of the transcriptional repression by c-fos is not clear. A cis-acting AP-1 element has been shown to be involved in IL-1 $\beta$-mediated repression of the $\alpha_{1}$-antichymotrypsin gene. ${ }^{45}$ Furthermore c-fos is a negative transcriptional regulator of myogenin. ${ }^{46} \mathrm{Re}-$ 
pression may only require physical interaction of c-fos with the cognate DNA binding site, dAP-1. This may explain why a dominant-negative c-fos, which lacks a trans-activation domain, repressed ASBT transcription, as well as a native c-fos expression construct. Binding of the c-jun/c-fos complex distal to the transcriptional initiation site may physically interfere with transcript elongation. IL-1 $\beta$ treatment is associated with the disappearance of ABP-2, which involves uAP-1, and therefore implies that binding by c-fos influences more than the dAP-1 site. Further studies will be required to define the exact mechanism by which c-fos binding inhibits ASBT transcription. In cell lines and in rat ileal epithelium, the transcriptional repression is associated with serine phosphorylation and nuclear translocation of c-fos. The biologic relevance of and mechanisms for phosphorylation of c-fos are not well understood. ${ }^{47}$

These studies have shown a new paradigm for the role of AP-1 in the transcriptional regulation of the rat apical sodium-dependent bile acid transporter (Figure 10). Intestinal inflammation is associated with enhanced expression of proinflammatory cytokines. These proinflammatory cytokines activate phosphatidylinositol 3-kinase and NF- $\kappa \mathrm{B}$ to mediate downstream effects on c-jun, c-fos, and other acute phase reacting proteins. The ASBT promoter does not contain a recognizable NF- $\kappa \mathrm{B}$ binding site. c-Fos is then phosphorylated and translocates into the nucleus, where it binds to the distal cis-acting AP-1 element. Transcription is then repressed by either direct physical effects on transcript elongation or indirect effects on the uAP-1-centered transcriptional complex. Future studies will be needed to assess whether this paradigm is also used in the repression of ASBT expression that has been observed during normal development and in response to the adaptive response to surgical resection of the intestine. ${ }^{48,49}$

\section{References}

1. Shneider B. Intestinal bile acid transport: biology, physiology and pathophysiology. J Pediatr Gastroenterol Nutr 2001;32:407-417.

2. Wong MH, Oelkers P, Craddock AL, Dawson PA. Expression cloning and characterization of the hamster ileal sodium-dependent bile acid transporter. J Biol Chem 1994;269:1340-1347.

3. Shneider BL, Dawson PA, Christie DM, Hardikar W, Wong MH, Suchy FJ. Cloning and molecular characterization of the ontogeny of a rat ileal sodium-dependent bile acid transporter. J Clin Invest 1995;95:745-754.

4. Christie DM, Dawson PA, Thevananther S, Shneider BL. Comparative analysis of the ontogeny of a sodium-dependent bile acid transporter in rat kidney and ileum. Am J Physiol 1996;271: G377-G385.

5. Alpini G, Glaser SS, Rodgers R, Phinizy JL, Robertson WE, Lasater J, Caligiuri A, Tretjak Z, LeSage GD. Functional expression of the apical $\mathrm{Na}^{+}$-dependent bile acid transporter in large but not small rat cholangiocytes. Gastroenterology 1997;113:1734-1740.

6. Lazaridis K, Pham L, Tietz, Marinelli R, deGroen P, Levine S,
Dawson P, LaRusso N. Rat cholangiocytes absorb bile acids at their apical domain via the ileal sodium-dependent bile acid transporter. J Clin Invest 1997;100:2714-2721.

7. Chignard N, Mergey M, Veissiere D, Parc R, Capeau J, Poupon R, Paul A, Housset C. Bile acid transport and regulating functions in the human biliary epithelium. Hepatology 2001;33:496-503.

8. Heubi JE, Balistreri WF, Fondacaro JD, Partin JC, Schubert WK. Primary bile acid malabsorption: Defective in vitro ileal active bile acid transport. Gastroenterology 1982;83:804-811.

9. Oelkers P, Kirby LC, Heubi JE, Dawson PA. Primary bile acid malabsorption caused by mutations in the ileal sodium-dependent bile acid transporter gene (SLC10A2). J Clin Invest 1997; 99:1880-1887.

10. Tougaard L, Giese B, Pedersen B, Binder V. Bile acid metabolism in patients with Crohn's disease in terminal ileum. Scand $J$ Gastroenterol 1986;21:627-633.

11. Farivar S, Fromm H, Schindler D, McJunkin B, Schmidt F. Tests of bile-acid and vitamin $\mathrm{B}_{12}$ metabolism in ileal Crohn's disease. Am J Clin Pathol 1980;73:69-74.

12. Krag B, Krag B. Regional ileitis (Crohn's disease): I. Kinetics of bile acid absorption in the perfused ileum. Scand J Gastroenter 1976;11:481-486.

13. Balistreri WF, Suchy FJ, Heubi JE. Serum bile acid response to a test meal stimulus: a sensitive test of ileal function. Journal of Pediatrics 1980;96(3 pt 2):582-589.

14. Heuman R, Sjodahl R, Tobiasson P, Tagesson C. Postprandial serum bile acids in resected and non-resected patients with Crohn's disease. Scand J Gastroenter 1982;17:137-140.

15. Nyhlin H, Brydon G, Danielsson A, Westman S. Clinical application of selenium $\left({ }^{75} \mathrm{Se}\right)$-labelled bile acid for the investigation of terminal ileal function. Hepatogastroenterology 1984;31:187191.

16. Sundaram U, Wisel S, Stengelin S, Kramer W, Rajendran V. Mechanism of inhibition of $\mathrm{Na}^{+}$-bile acid cotransport during chronic ileal inflammation in rabbits. Am J Physiol 1998;275: G1259-G1265.

17. Stelzner M, Somasundaram S, Khakberdiev T. Systemic effects of acute terminal ileitis on uninflamed gut aggravate bile acid malabsorption. J Surg Res 2001;99:359-364.

18. Gross V, Andus T, Leser H, Roth M, Scholmerich J. Inflammatory mediators in chronic inflammatory bowel diseases. Klin Wochenschr 1991;69:981-987.

19. Shih D, Bussen M, Sehayek E, Ananthanarayanan M, Shneider B, Suchy F, Shefer S, Bollileni J, Gonzalez F, Breslow J, Stoffel M. Hepatocyte nuclear factor- $1 \alpha$ is an essential regulator of bile acid and plasma cholesterol metabolism. Nature Genetics 2001;27: 375-382.

20. Chen F, Ma L, Al-Ansari N, Shneider B. The role of AP-1 in the transcriptional regulation of the rat apical sodium-dependent bile acid transporter. J Biol Chem 2001;276:38703-38714.

21. Koj A. Initiation of acute phase response and synthesis of cytokines. Biochim Biophys Acta 1996;1317:84-94.

22. Yamada T, Deitch E, Specian R, Perry M, Sartor R, Grisham M. Mechanisms of acute and chronic intestinal inflammation induced by indomethacin. Inflammation 1993;17:641-662.

23. Han D, Li F, Holt L, Connolly K, Hubert M, Miceli R, Okoye Z, Santiago G, Windle K, Wong E, Sartor B. Keratinocyte growth factor-2 (FGF-10) promotes healing of experimental small intestinal ulceration in rats. Am J Physiol 2000;279:G1011-G1022.

24. Chomczynski P, Sacchi N. Single-step method of RNA isolation by acid guanidinium thiocyanate-phenol-chloroform extraction. Anal Biochem 1987;162:156-159.

25. Shneider BL, Thevananther S, Moyer MS, Walters HC, Rinaldo P, Devarajan P, Sun AQ, Dawson PA, Ananthanarayanan M. Cloning and characterization of a novel peptidase from rat and human ileum. J Biol Chem 1997;272:31006-31015.

26. Zagariya A, Mungre S, Lovis R, Birrer M, Ness S, Thimmapaya B, 
Pope R. Tumor necrosis factor alpha gene regulation: Enhancement of C/EBP $\beta$-induced activation by C-Jun. Mol Cell Biol 1998; 18:2815-2824.

27. Johnson A, Murphy B, Matelis C, Rubinstein Y, Piebenga E, Akers L, Neta G, Vinson C, Birrer M. Activator protein-1 mediates induced but not basal epidermal growth factor receptor gene expression. Mol Med 2000;6:17-27.

28. Barbu V, Dautry F. Northern blot normalization with a $28 \mathrm{~S}$ rRNA oligonucleotide probe. Nucl Acids Res 1989;17:7115.

29. Arrese M, Trauner M, Sacchiero RJ, Crossman MW, Shneider BL. Neither intestinal sequestration of bile acids nor common bile duct ligation modulate the expression and function of the rat ileal bile acid transporter. Hepatology 1998;28:1081-1087.

30. Zhu C, Gagnidze K, Gemberling J, Plevy S. Characterization of an activation protein-1 binding site in the murine interleukin-12 p40 promoter: Demonstration of novel functional elements by a reductionist approach. J Biol Chem 2001;276:18519-8528.

31. Brown P, Kim S, Wise S, Sabichi A, Birrer M. Dominant-negative mutants of cjun inhibit AP-1 activity through multiple mechanisms and with different potencies. Cell Growth Differ 1996;7:10131021.

32. Olive M, Krylov D, Echlin D, Gardner K, Taparowsky E, Vinson C. A dominant negative to activation protein-1 that abolishes DNA binding and inhibits oncogenesis. J Biol Chem 1997;272:1858618594.

33. Zerivitz K, Akusjarvi G. An improved nuclear extract preparation method. Gene Anal Tech 1989;6:101-109.

34. Rondon I, MacMillan L, Beckman C, Goldberg M, Schneider T, Bunn $\mathrm{H}$, Malter J. Hypoxia up-regulates the activity of a novel erythropoietin mRNA binding protein. J Biol Chem 1991;266: 16594-16598.

35. Anderson D, Blobel G. Immunoprecipitation of proteins from cellfree translations. Methods Enzymol 1983;96:111-120.

36. Sun A, Swaby I, Xu S, Suchy F. Cell-specific basolateral membrane sorting of the human liver $\mathrm{Na}+$-dependent bile acid transporter. Am J Physiol 2001;280:G1305-G1313.

37. Hellerbrand C, Jobin C, limuro Y, Licato L, Sartor R, Brenner D. Inhibition of NFkappaB in activated rat hepatic stellate cells by proteasome inhibitors and an IkappaB super-repressor. Hepatology 1998;27:1285-1295.

38. Reddy S, Huang J, Liao W. Phosphatidylinositol 3-kinase in interleukin 1 signaling. J Biol Chem 1997;272:29167-29173.

39. Lee W, Mitchell P, Tijan R. Purified transcription factor AP-1 interacts with TPA-inducible enhancer elements. Cell 1987;49: 741-752.
40. Sundaram U, West A. Effect of chronic inflammation on electroIyte transport in rabbit ileal villus and crypt cells. Am J Physiol 1997;272:G732-G741.

41. Sundaram U, Wisel S, Fromkes J. Unique mechanism of inhibition of $\mathrm{Na}+$-amino acid cotransport during chronic ileal inflammation. Am J Physiol 1998;275:G483-G489.

42. Sundaram U, Wisel S, Rajendren V, West A. Mechanism of inhibition of $\mathrm{Na}^{+}$-glucose cotransport in the chronically inflamed rabbit ileum. Am J Physiol 1997;273:G913-G919.

43. Daun J, Fenton M. Interleukin-1/Toll receptor family members: receptor structure and signal transduction pathways. J Interfer Cytokine Res 2000;20:843-855.

44. Sizemore N, Leung S, Stark G. Activation of phosphatidylinositol 3-kinase in response to interleukin-1 leads to phosphorylation and activation of NF-kappaB p65/RelA subunit. Mol Cell Biol 1999;19:4798-4805.

45. Kordula T, Bugno M, Rudel R, Travis J. Mechanism of interleukin-1- and tumor necrosis factor alpha-dependent regulation of the alpha 1-antichymotrypsin gene in human astrocytes. J Neurosci 2000;20:7510-7516.

46. Daury L, Busson M, Tourkine N, Casas F, Cassar-Malek I, Wrutniak-Cabello C, Castellazzi M, Cabello G. Opposing functions of ATF2 and fos-like transcription factors in c-jun-mediated myogenin expression and terminal differentiation of avian myoblasts. Oncogene 2001;20:7998-8008.

47. Chen R, Juo P, Curran T, Blenis J. Phosphorylation of c-Fos at the c-terminus enhances its transforming activity. Oncogene 1996; 12:1493-1502.

48. Shneider B, Setchell KDR, Crossman M. Fetal and perinatal expression of ileal and renal sodium-dependent bile acid transport in the rat. Pediatr Res 1997;42:189-194.

49. Coppola CP, Gosche JR, Arrese M, Ancowitz B, Madsen J, Vanderhoof J, Shneider BL. Molecular analysis of the adaptive response of intestinal bile acid transport after ileal resection. Gastroenterology 1998;115:1172-1178.

Received April 11, 2002. Accepted April 29, 2002.

Address requests for reprints to: Benjamin Shneider, M.D., Mount Sinai School of Medicine Box 1656, One Gustave L. Levy Place, New York, New York 10029. e-mail: Benjamin.Shneider@mssm.edu; fax: (212) 427-1951.

Supported by National Institutes of Health grants DK 02076, DK 54165, DK 34987, and DK 40249, and a research grant from Lehman Brothers. 